ENTORNOS, No. 27. | Abril 2014

ARTÍCULO DE INVESTIGACIÓN

Recibido: 4 Febrero / Recibido en forma revisada: 5 Marzo / Aceptado: 12 Abril

\title{
Presencia Árabe en Neiva
}

\section{Arab Presence en Neiva City}

\section{Arabische Präsenz en Neiva}

\author{
Benjamín Alarcon Yustres ${ }^{1}$, Ángela Adriana Segura Pérez ${ }^{2}$
}

\begin{abstract}
Resumen
El artículo hace seguimiento al proceso migratorio de árabes que llegaron al territorio de lo que hoy configura el Departamento del Huila, su asentamiento en él y la articulación a los procesos económicos, sociales y culturales de este. El proceso comenzó tras migrar de los territorios que hoy configuran el Libano, Siria y Palestina, durante las dos últimas décadas del siglo XIX, cuando estos hacían parte del Imperio Turco Otomano, y se extendió hasta la segunda mitad del siglo XX, cuando se creó el Estado de Israel como resultado de los acuerdos de las potencias que participaron en la Segunda Guerra Mundial y se produjo la última oleada migratoria del Territorio Palestino. A Colombia la migración árabe se hizo esencialmente por el caribe, en el que Puerto Colombia constituyó el puerto de arribo y Barranquilla la ciudad en la que se instaló la mayor cantidad de ella. Desde ahí se expandió por la costa y luego hacia el interior de esta hacía el sur siguiendo el curso del Río Sinú; y hacia el interior del país siguiendo el curso del Río Magdalena, sobre el cual establecieron la mas importante colonia árabe en Girardot desde donde remontaron las cordilleras oriental y central para llegar a Santafé de Bogotá y al Valle del Cauca. Y desde ahí también siguieron al sur hasta llegar a Neiva, el Huila y la Amazonía; territorios estos aislados y marginados de los centros de poder y solo conectados al mundo por su producción de las materias primas necesarias y apetecidas por el capitalismo para su desarrollo y expansión: la quina y el caucho.
\end{abstract}

Palabras clave: Migración, Árabes, Libaneses, Sirios, Palestinos, Neiva.

\section{Abstract}

The article does a follow up to the Arab Migratory Process that came into the Huila State territory, their settlement and the economic, social and cultural processes articulations. The process began after the migration from the territories that are Lebanon, Syria and Palestine today during the last two decades of 19th century, when these people were part of the Ottoman Turkish Empire, and it extended until half of 20th century, when Israel State was created as a result of the World Powers Agreements that participated in World War II and the first big migratory wave of the Palestinian Territory was produced. In Colombia, the Arab Migration was done specially thru the Caribbean and Puerto Colombia (Colombian port) was the arrival port for them. Barranquilla was the city in which most of this population went to live. From there, they extended throughout the coast and then into the inner part towards South following the Sinú River course; and more into the country following the Magdalena river course, in which the most important Arab Colony was established in a city called Girardot. From here, they overcame the Central and East mountain ranges to arrive to Santa Fé de Bogotá and Valle del Cauca. From there, they continued going South to arrive to Neiva City, Huila State and the Amazon region; isolated and marginalized territories from the power centers and only connected to the world by its needed raw materials production that are consumed by capitalism for its development and expansion: Quina and Rubber.

Keywords: Migration, Arabs, Lebanese, Syrian People, Palestine's, Neiva.

\section{Zusammenfassung}

Der Artikel beobachtet den Migrationsprozess der Araber, die in das Gebiet der heutigen Provinz Huila kamen, ihre Ansiedlung und die damit verbundenen ökonomischen, sozialen und kulturellen Prozesse.

Der Prozess begann durch die Migration aus den Gebieten des Libanon, Syriens und Palästinas während der zwei letzten Dekaden des 19. Jahrhunderts, als diese Teil des Osmanischen Reiches waren, und dauerte bis zur Mitte des 20. Jahrhunderts an, als der Staat Israel gegründet wurde als Ergebnis des Mächteabkommens nach dem 2. Weltkrieg, welches die letzte Migrationswelle aus dem Gebiet Palästinas auslöste.

1 - Magister en Conflicto, Territorio y Cultura Universidad Surcolombiana. Neiva. Colombia. benalar57@gmail.com

2 - Magister en Conflicto, Territorio y Cultura Universidad Surcolombiana. Docente Gimnasio Yumaná. Neiva. Colombia. 
In Kolumbien erfolgte die arabische Einwanderung vor allem über die Karibik, wobei Puerto Colombia den Haupteinreisehafen darstellte und Barranquilla die Stadt war, in der sich der Großteil der Einwanderer niederließ. Von hier breiteten sie sich entlang der Küste aus, dann weiter ins Landesinnere und schließlich entlang des Río Sinú bis in den Süden des Landes und entlang des Río Magdalena, an dem die wichtigste Kolonie arabischen Urpsrungs namens Girardot gegründet wurde. Von hier aus stiegen sie die östlischen und zentralen Kordilleren hinauf, um schließlich nach Santafé de Bogotá und in das Valle de Cauca zu gelangen. Auch von hier aus gingen sie noch weiter nach Süden bis nach Neiva, Huila und nach Amazonien, in Gebiete, die sehr isoliert waren und abseits der Machtzentren lagen, nur durch die Produktion notwendiger Rohstoffe und dem Verlangen des Kapitalismus an Entwicklung und Expansion mit der Welt verbunden: Chinarinde und Kautschuk.

Este artículo aborda el tema de la migración árabe a Neiva, en el periodo comprendido entre las dos últimas décadas del siglo XIX y los años 80 del siglo XX; en esa medida alude a las razones y condiciones en que se produjo la salida de los miembros de esta comunidad de los territorios en que habitaban, la trayectoria seguida y las razones y condiciones de llegada al país y a la región, así como su articulación a los procesos económicos, sociales y culturales de la ciudad.

De entrada es necesario precisar cosas. Los árabes a los que se refiere el artículo habitaban el territorio que hoy comprenden Líbano, Siria y Palestina, de lengua, costumbres, prácticas y algunas creencias árabes, aunque en materia religiosa los que llegaron a estas tierras hasta antes de 1948, eran maronitas, la mayoría, y solo en pocos casos drusos, y musulmanes los que llegaron después de la creación del Estado de Israel. Y como el territorio de donde provenían era dominio del Imperio Turco Otomano, salían con pasaporte de Turquía, por lo que al llegar recibían el apelativo de turcos. Esta precisión es necesaria por cuanto muchos moros se alistaron en los contingentes colonizadores que llegaron a América a partir del mismo año en que se produjo su expulsión de España, en 1492, pero llegaron como españoles porque la condición puesta por la monarquía para permanecer en España era convertirse al cristianismo e integrarse a la cultura española; así que a estos no hace alusión este artículo.

La segunda precisión necesaria es que la Neiva a la que nos referimos es la ciudad región, a la manera como la explican Juan Álvaro Echeverry y Gerardo Ardila: como el espacio en el que se construye un poder en tensión con otros; "el lugar material donde se producen las relaciones de poder que configuran la territorialidad, que es el dominio que se ejerce o se vive sobre un pedazo de territorio a partir del rol que se cumple en esas relaciones de poder", como lo dice Ardila (Echeverry y Ardila. 2006). Neiva es la ciudad eje desde la cual ese poder se ha extendido en el espacio hasta configurar un territorio en el que impuso sus relaciones de poder; con denominaciones distintas durante la Nueva Granada, como parte del Estado soberano del Tolima durante los Estados Unidos de Colombia e integrante del Departamento del Sur, o como la Provincia de Neiva, una de las dos en que se divide en 1905 el recién creado Departamento del Huila.
Los árabes que llegaron a Colombia lo hicieron en tres grandes oleadas provocadas por sendos hechos históricos acaecidos en los lugares de procedencia. La primera oleada se produjo a partir de 1880 como consecuencia de la guerra religiosa en la que los drusos (minoría religiosa islámica integrada por árabes esencialmente, que difiere de los grupos islámicos mayoritarios chiis y suní, creada hacia el año 1100) apoyados por los turcos, produjeron la muerte de aproximadamente veinte mil cristianos maronitas, (llamados también cristianos de oriente, que se caracterizan por su vínculo estrecho y leal a Roma; hoy se les considera los católicos de oriente, con asiento sobre todo en Líbano y Siria; su origen se remonta al año 400, cuando surgieron de entre los seguidores de un cristiano anacoreta llamado Marón) quince mil libaneses y cinco mil sirios. El territorio de lo que hoy es Líbano, Siria, Palestina e Israel, fue dominio del Imperio Turco Otomano hasta la Primera Guerra Mundial, cuando éste desaparece, y se convirtió en protectorado francés e inglés; aunque también el territorio de lo que hoy es Líbano fue, tras la primera cruzada cristiana, dominio franco hasta casi el año 1300 , cuando fueron expulsados los cruzados por los musulmanes, razón que explica también la influencia cultural francesa en ese pedazo de territorio del cercano oriente.

La segunda y más importante oleada se produjo en el periodo comprendido entre la primera y la segunda guerras mundiales. Tras los acontecimientos de la primera guerra, Líbano fue sitiado por todos los flancos y sometido a la peor crisis humanitaria jamás vivida: el Imperio Turco Otomano lo sitió por tierra, aislándolo del resto de Asia, mientras los aliados europeos con Francia e Inglaterra a la cabeza, hicieron lo propio por el mar Mediterráneo, aislándolo de Europa; la consecuencia fue una hambruna en la que perecieron más de un millón de habitantes, casi un tercio de su población, y el desplazamiento de gran cantidad de sobrevivientes. Y la tercera oleada se produjo tras la Segunda Guerra Mundial como consecuencia de los conflictos internos en unos territorios que habían adquirido autonomía e identidad como países, tras la desaparición del Imperio Turco Otomano que los oprimía, y tras la independencia de Francia e Inglaterra que después de la Primera Guerra los había convertido en protectorados; ahora las distintas facciones políticas y religiosas pugnaban por el poder en una región en la que había aparecido un nuevo factor de conflicto: el Estado de Israel. (Héctor Romano Marún. 1985) 
En esas circunstancias se producen las migraciones de árabes a Colombia que provienen esencial y mayoritariamente de Libano y en menor cantidad de Siria y Palestina; (Behaine de Cendales. 1996). Los árabes de la primera oleada, así como parte de los de la segunda, realmente migraron a América, ilusionados con la prosperidad y la libertad; América era Estados Unidos, que como consecuencia de sus políticas migratorias había cerrado fronteras a los inmigrantes, razón por la cual los migrantes terminaban en las costas de islas como Cuba o de América Central o del Sur, tras deambular por el Caribe. Por eso llegaron a las costas colombianas, específicamente a la costa norte Caribe, por Puerto Colombia, se establecieron en Barranquilla y desde ahí se dispersaron costa sur, y luego se internaron por la región costera utilizando los cauces de los ríos Sinú y San Jorge y simultáneamente por el Río Magdalena lo hicieron hacia el interior del país. (op cit)

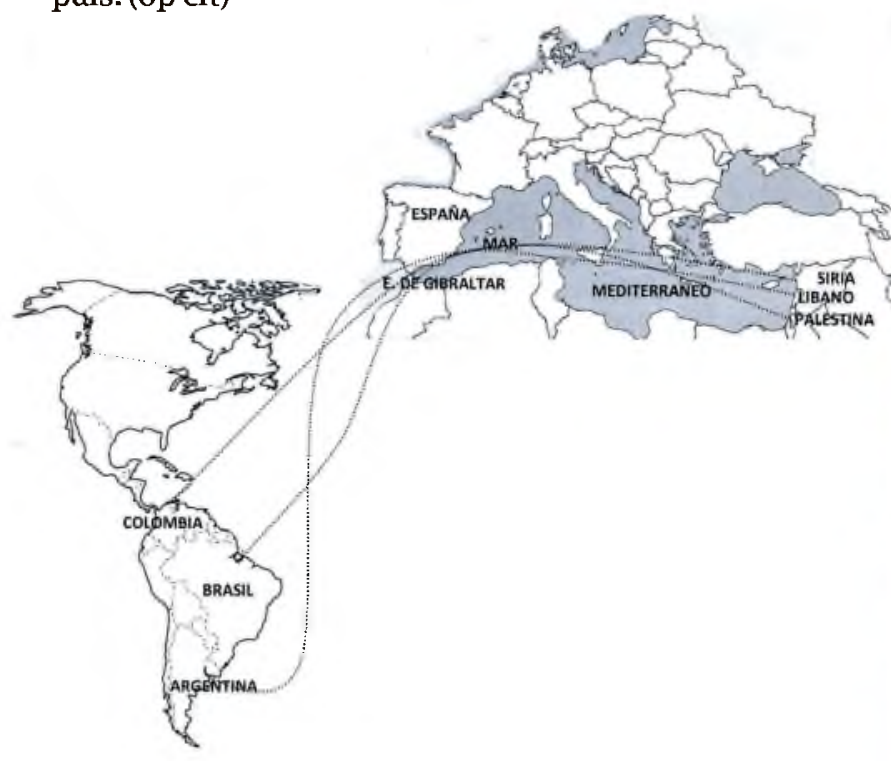

Gladys Behaine de Cendales dice que "Cronológicamente se registran como iniciadores de la inmigración a Colombia, entre otros, a Assad Behaine, quien arribó en 1885; Moisés Jattin en 1890, quien se estableció en Lorica. Seguidamente miembros de las familias Baruqui, Fayad, Barbur, Helo, Turbay, Resk, Mor, Matu, Fadul, Mebarak, Guerra y Ayubb" (Behaine de Cendales. 1996). Y se dedican al comercio preferentemente por una razón histórica elemental: provienen esencialmente de lo que hoy es Líbano, epicentro del antiguo imperio fenicio, constituido por un pueblo que desarrolló la navegación marítima por el Mediterráneo y a través de ésta promovió el comercio entre los pueblos que vivían en sus márgenes y alrededores; en esos escenarios de intercambio construyeron fortalezas entre las cuales la más conocida fue Cartago pero también Biblos, Tiros, Sidón, Trípoli, y de los cuales muchos libaneses se sienten herederos. (Op cit)

Por eso los que se internaron en el país siguiendo el curso del Río Magdalena, aguas arriba, hacia el sur, desembarcaban en los lugares de parada y se establecían ahí o continuaban camino en busca de nichos de mercado para su oficio en otros poblados; es lo que explica la importante presencia de árabes durante ese periodo en los Santanderes, particularmente en Ocaña y Bucaramanga. Y como Bogotá era la capital de la república, la aspiración de muchos era llegar allí, pero la única ruta y los únicos medios posibles por entonces para llegar al interior del país eran el Río Magdalena y el champán y los barcos de vapor, por lo que debían obligatoriamente bajarse en el lugar apropiado y coger camino al oriente; ese lugar era Girardot, razón que explica que una mayoría se estableciera ahí y configurara la más grande colonia árabe del interior del país. Según estadísticas mencionadas por Hakim, en 1930 el $10 \%$ de la población de este puerto fluvial era árabe y controlaba el comercio del puerto desde donde a su vez se controlaba el comercio hacia y desde Bogotá y el sur del país; en 1932 Julio César Turbay Ayala fue nombrado alcalde de ese municipio. (Hakim Murad. 1993).

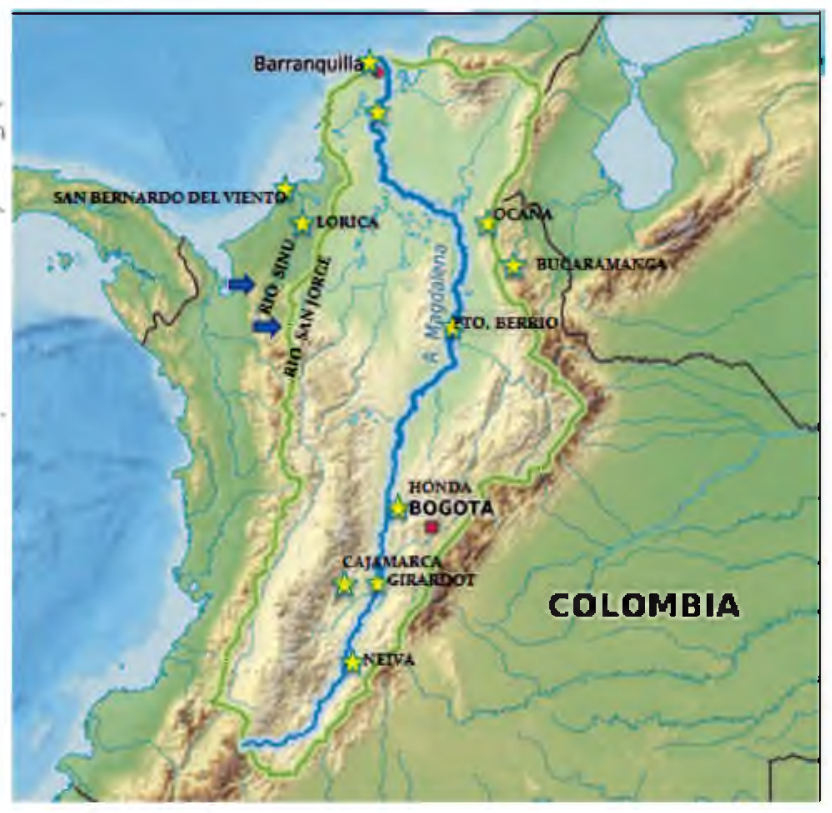

Fue por tanto desde ahí, desde Girardot, desde donde se produjo la migración de árabes a Neiva, a pesar de que el propio Hakim Murad plantea la versión de que a la Provincia o a la región llegaron árabes hacia finales del siglo XIX, seguramente siguiendo el curso del negocio de la quina o del caucho. Eso porque Neiva y la región vivieron desde la década de 1860 las bonanzas de la quina, primero, sobre la ladera occidental del cordillera oriental, y luego, en menor grado, del oro sobre la ladera oriental de la cordillera central y del caucho sobre la ladera oriental de la Cordillera Oriental, en la Amazonía colombiana. La plantación más importante de quina que hubo en la provincia y la región fue en San Francisco, hoy Colombia, Huila, de la Compañía Colombia fundada en 1863 con capital Antioqueño de Jorge Child, Carlos Michelsen, Nazario Lorenzana, Bernardo Herrera y el cura Agustín Peñuela, que era dueño de las tierras de San Francisco; 
la compañia llegaba hasta San Martín, Meta, y por eso fundó varias haciendas para producir los alimentos para los peones que extraían la quina. También entre San Agustín y el Valle del Río Suaza prosperó su producción operada allí por la Compañia Lorenzana de Cuellar, Durán, Angel y Co. y el propio Nazario Lorenzana; esta empresa se caracterizó porque a la extracción del producto vinculó muchos indígenas del sur del departamento y del sur del país. En 1860 buena parte de lo que hoy es el Departamento estaba despoblada y su población se asentaba preferentemente sobre el valle del Río Magdalena; Neiva, por entonces, 1870, tenía solo 8.332 habitantes. Así que seguramente tras esas bonanzas pasaron o llegaron por otros caminos algunos árabes. (Tovar Z. 1996).

A finales de siglo, Neiva y la región sintieron los efectos de los conflictos que vivía el país tras la nueva Constitución, la de 1886, que pretendía construir una nación centralizada, gobernada desde Bogotá por una élite que desconocía la periferia fragmentada y desconectada por la carencia de vías y medios de transporte y comunicación e integrada por una sociedad que dichas élites ignoraban; las secuelas de la Guerra de los Mil Días fueron muertos humanos y pobreza por las enormes pérdidas de cabezas de ganado vacuno y caballar puesto a disposición de los partidos en conflicto, con hatos devastados y hacendados con dificultades para afrontar sus compromisos; iguales dificultades vivían campesinos en condición de siervos, jornaleros y aparceros; Huila era una región agrícola y ganadera en la que estos últimos producian bienes agrícolas y cuidaban y hacian producir el ganado del cual los hacendados eran dueños junto con la tierra; entre estos y aquellos se producen hechos que marcaron el inicio de un conflicto que maduraria años después, particularmente relacionados con baldíos limpiados y puestos a la producción de café, recién traído, que los terratenientes apropiaban una vez limpios; y por último la partición de los antiguos Estados soberanos en departamentos para debilitar el viejo poder liberal tras la derrota en la guerra, razón por la cual se crea en 1905 el Departamento del Huila, en las mismas condiciones de aislamiento y desconexión de finales de siglo. Al lado y simultáneamente a esos hechos que marcaron ese momento de la historia del país, un hecho importante prosperaba en silencio: desde 1880 la Compañía Colombia, extractora y exportadora de quina, habia traído las primeras plantas de café que los campesinos comenzaron a sembrar sobre las laderas de la cordillera oriental; el cultivo y la producción sobre una región climáticamente apropiada para ello contribuirá a cambiar el panorama económico y social de Neiva en el nuevo siglo.

En ese contexto es que llegan los árabes a Neiva. Eduardo Hakim Murad menciona, a propósito de cuatro hermanos Fadul que llegaron al país por Barranquilla, el caso de Ignacio, de quien dice que "resolvió viajar al Huila del que había recibido buenas referencias sobre la calidad de las gentes por parte de don Felipe Abdalá, quien le informó que.........Fue a radicarse bien lejos, en el extremo sur de ese departamento, en Timaná.....aislada totalmente de Neiva y del centro del país, a donde únicamente se podía llegar a lomo de mula, por caminos enfangados e intransitables para otro tipo de cabalgadura....Llegó antes de la guerra de los mil días y organizó un negocio también de doble vía. Llevaba la producción de sombreros y cacao comprados casi todos en Timaná y en Suaza, artículos que luego de cargarlos cuidadosamente sobre una recua de mulas que viajaba con él a la cabeza...... Hasta llegar a Neiva y al Guamo en el Tolima.... Regresaba al mes con telas y variadas mercancías que vendía al fiado a las gentes de Timaná y sus veredas, pagaderas a la cosecha de café." (op cit)

Pero tal como se afirma atrás, Ignacio Fadul llegó al Huila por recomendación de Felipe Abdalá quien al parecer ya hacía lo que después haría su paisano: organizó un negocio paralelo al de don Felipe Abdalá, otro libanés que hacía los mismos recorridos y comerciaba de igual manera, con sombreros, panela, cacao, mercancías y telas adquiridas para el regreso al sur, en el Almacén "La cinta Roja", de Girardot." (op cit pag 238). Don Felipe se estableció en Garzón un año después de haber llegado a Cartagena, y finalmente lo hizo también en Tímaná. El cacao había sido el producto natural de mayor producción en la tradicional hacienda agrícola de la región.

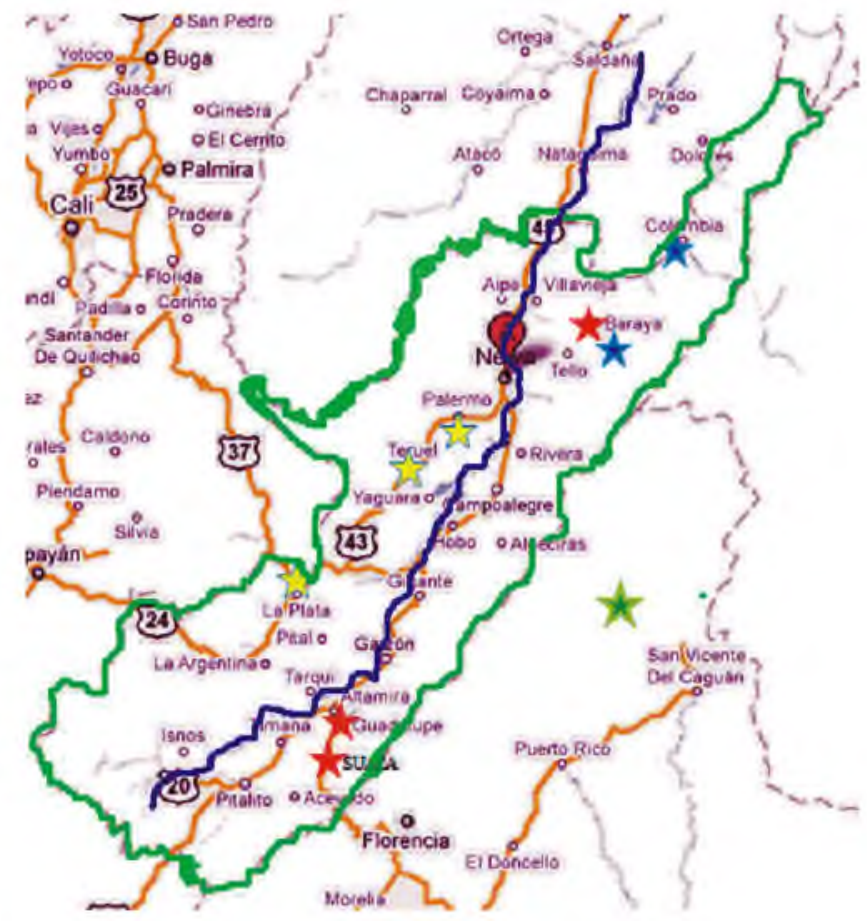

El negocio de los sombreros suaceños atrajo a otro árabe que había llegado al país en 1907, e inmediatamente viajó a Girardot y de ahí a Suaza, donde negoció directamente con los artesanos toda la producción, y gracias al contacto con una hermana suya en Estados Unidos, se dedicó durante un buen tiempo a la exportación de los sombreros a ese país; 
José Náder se llamaba el árabe y fue promotor de la exportación de uno de los productos que sustituyó durante ese periodo las bonanzas exportadoras que había tenido o habían afectados de distintas maneras a Neiva y la región desde 1860: la de quina, primero, el oro y el caucho después, y antes de que despuntara la producción de café que se convertiría, entrando el siglo XX, en el principal producto de exportación.

Siguiendo el curso de las circunstancias de tiempo y modo de llegada de los árabes a Neiva, Guillermo Plazas Alcid dice a propósito de su abuelo que "él haciendo alusión a su padre-como que le tocó ver que le mataran a su padre en el Vaupés pues era comerciante o contrabandista, la verdad no se bien que hacía el abuelo allá y pues él, mi abuelo, era el inmigrante, el viejo; mi padre nació aquí en Neiva y pagó el servicio militar cuando el conflicto con el Perú; mi padre, un hijo de libanés que se llamaba Alfredo Alcid Aljure, nació en Neiva; eran cuatro hermanos, eran Gabriel, Carlos, Soraya y Alfredo; la madre de ellos se ahogó aquí en el río Magdalena" (Plazas Alcid 2009). Ese testimonio mostraría que por el mismo periodo o seguramente antes había llegado al territorio de Neiva o del sur, Alfredo Alcid, el inmigrante libanés, casado con Rosa Aljure, abuelo de Guillermo Plazas, padre de Alfredo Alcid Aljure, quien habría llegado a comercializar "pues era comerciante o contrabandista", dice, para aludir a la actividad a la que se dedicaban todos o la mayoría de los árabes que llegaron al país; el Vaupés hace parte de la Amazonía colombiana que por esa época constituía el territorio de donde se extraía el caucho para exportar a Europa y Estados Unidos, utilizando la ruta del rió Amazonas por Brasil y en pocos casos, la del Río Magdalena, por Colombia. Así que se presumiría que Alcid comerciaba con caucho o con productos requeridos por los caucheros, aunque no se precisa si su llegada al país se produjo por Brasil o Colombia siguiendo el curso del Magdalena.

Otro árabe que habría llegado a finales del siglo XIX a Neiva y el sur de Colombia, fue Abdo Antonio Rujana, quien vino al país por Barranquilla junto con dos hermanos que siguieron para la Argentina, y su esposa Nayibe Sarquís Faysal; este personaje establece relación inmediata en Neiva con Leonidas Lara, un próspero empresario de cuyo origen solo se sabe que era natural de Yaguará, pero que haría parte de esa oleada de árabes o judíos que llegaron al país en la década de 1880 e inmediatamente se trasladaron al sur, seguramente tras el comercio de quina o caucho, o de mercancías requeridas en la región.

Abdo instaló uno de los primeros almacenes de comercio en Neiva, que daba crédito pagadero con la cosecha; uno de los clientes fue un señor José Mario Velosa, quien adquirió un crédito que al no poder pagar, lo obligó a entregarle su finca llamada Municiones en la localidad de Vegalarga, cerca a Neiva; ahí se producirá el asesinato del único hombre- su cuñado- de la familia Sarquich, compuesta por cuatro hermanas y él, del que se acusó al propietario de la hacienda contigua llamada El Cedral, Jorge Villamil Ortega, hecho trascendente en la historia de la región en el que intervendrá como abogado penalista Jorge Eliecer Gaitán en nombre de la familia Sarquich, y quien renunciará al caso cuando se prueba que el comandante de la policía interviene junto con el juez para quemar los archivos que comprometían al acusado. El crimen quedó impune no obstante la intervención del gobierno de López Pumarejo por presión del gobierno francés dada la nacionalidad del asesinado.

A Pitalito llegaron también a comienzos del siglo XX dos hermanos Arana Spirt, Jacob y Salvador, procedentes de Damasco, Siria, quienes montaron una venta de colchones, el primero, y un almacén de telas, el segundo. Luego lo hicieron Jorge Saab y Camilo Saab, y un personaje notable en la vida social y política del municipio primero y del departamento después, que había nacido en Girardot, pero pequeño, de tres años, los padres lo llevaron de regreso al Líbano donde se enroló en las huestes maronitas que se oponían a los ataques drusos, por lo que sus padres lo enviaron nuevamente a Colombia; este árabe se llama Edmundo Aljach Zajar, que se destacó en Pitalito por ser líder deportivo por cuanto había sido campeón mundial de boxeo antes de regresar a Colombia, y luego como líder político y funcionario público durante 16 años en el Departamento; fue diputado de la Asamblea departamental.

Bien entrado el siglo $\mathrm{XX}$, en pleno desarrollo de la producción cafetera y cuando el Departamento promueve su articulación al país a través del avión y el ferrocarril y por carreteras entre sus poblados, se producen las siguientes oleadas de migrantes que llegan en condiciones económicas distintas, ya articulados a las redes de familias y paisanos que los primeros habían organizado; llegan Lázaro Aljure, Mantura Murad,- hermana de Elías y José que habían pasado de largo hacia el Amazonas a negociar con quina y caucho y murieron envenenados -, Jorge Esper, Ricardo y luego Atala Esper Tapicha, junto con dos sobrinos; Teófilo Hakim y su esposa Nelly Muradquienes deambularon por distintos pueblos del Tolima (Ortega, Ibagué , Líbano, Cajamarca) antes de llegar a Neiva; Teofilo y Elías Zajar, Alfredo Cassir, Camilo Saab, Ignacio Fadul, Gabriel Aljure, Moises Gechem (venido en 1929), las tres hermanas Sarquís, cuñadas de Abdo Antonio Rujana esposo de Nayibe Sarquís Faysal, quienes habían llegado con sus dos padres en 1912 y luego en 1918 fueron por los otros dos hermanos; Abbas Turbay, quien realmente vivía en el Caquetá donde poseía una inmensa hacienda, y Felipe Abdala, quien había regresado de Timaná e instalado en Neiva, tras haber viajado al Líbano a traer esposa. Igualmente Costi, Jorge, Lela y Nayib Ababuat, que se habían instalado en Garzón, y León Galat, de origen sirio. Por último los hermanos Amar, José y Manuel, que eran drusos, a diferencia de casi todos los libaneses y sirios venidos a Neiva hasta entonces; José había sido miembro de la caballería imperial del Ejercito otomano. 
En Baraya se instalaron los hermanos Daniel, Juan y Karim Sefaer, José Chalela, Moises Gechem, quien se había casado con Silvia Turbay, hija de Abbas Turbay, y Alfredo Alcid Aljure, padre de Guillermo Plazas Alcid. La razón que explica esta colonia de árabes en Baraya es que este poblado denominado Santa María de la Nutria, fue el lugar de paso hacia la famosa Empresa Colombia, que explotaba quina durante el periodo de bonanza de este producto, a finales del siglo XIX; la empresa estaba ubicada en lo que hoy es el Municipio de Colombia, entonces San Francisco, y Baraya era la estancia de paso de quienes viajaban hacia allá o de regreso, tras o para coger el medio de transporte en el río Magdalena, en la zona de Villavieja.

Después llegarían a Neiva Pablo Morón, en 1948, y Tonny Freiye Zajar, en 1952; Tonny hacía parte de la familia de los Zajar que había llegado a comienzos de siglo a Neiva; fue él quien trajo de regreso a Admundo Aljach Zajar.

Se ha repetido aquí que en general los árabes que llegaron a Colombia se dedicaron al comercio; y que por la condición económica en que venían, ese comercio lo adelantaron en principio de manera ambulante, de puerta en puerta, y que solo cuando lograron estabilizar un capital significativo montaron almacenes o tiendas fijas en las que vendían al fiado etaminas, sedas chinas, popelinas americanas, estampados, medias, mantas, toallas, ropa interior, pañolones, paños, driles, lonas, liencillos, etc. Sobre ello Ezedin Sabbag, Sirio llegado en los años 80, dice en un castellano aún difícil: "cuando llegaron al principio ellos empezaron, por ejemplo ..van a un almacén grande que tienen y dicen..miren yo quiero trabajar, entonces les fían, les dan crédito, es decir, van poco a poco y si en el primer viaje le dan poquito y cumple -y la mayoría eran cumplidos, pues no hay estafa, ni nada de esto-entonces en el otro viaje les dan y vuelven y les dan, y cuando ellos ya tienen algún capital ya ellos abrieron su propio negocio, (y ) el que llegaba nuevo llegaba donde ellos, entonces les fiaban al nuevo". (Ezedin Sabbag 2009). Para Ezedin es la red social la que facilita y promueve este proceso migratorio y su articulación a los procesos económicos y sociales.

Esa dinámica les permitió acumular capital muy rápidamente y vincularse a otras actividades económicas, tener reconocimiento social y articularse a la política; Abbas Turbay Turbay, por ejemplo, se dedicó a la tierra; organizó la hacienda La Estrella, en Guacamayas, Caquetá, desde donde cada tres meses viajaba a Neiva donde manejaba su capital y sus inversiones, porque había consolidado una red de relaciones sociales entre las élites con quienes departía siempre que llegaba a la ciudad; por eso cuando Reynaldo Matiz convoca a los ricos de la ciudad y la región para que hicieran posible el proyecto de la primera empresa de aviación en el país, Scatda, Abbas Turbay adquiere cinco acciones de la empresa en 1921.

Las relaciones sociales también se consolidaban a través de los matrimonios de los hijos; y se efectuaban con paisanos o con nativos: José Náder se casó con una giganteña, hija de una prestante familia de esa localidad; la hija de Abbas Turbay, Silvia, se casó con Moises Gechem Chalela en la hacienda Guacamayas; Gechem, que había llegado de 17 años al país, y Silvia, vivieron en Baraya, donde nació Jorge Eduardo, que sería después un reconocido dirigente liberal del departamento y del país.

Otro nicho económico al que se vinculan los árabes en Neiva es el de los hoteles justamente cuando el flujo de personas a la ciudad aumenta como consecuencia de la llegada del tren y la apertura de carreteras que comunican a Neiva con otros poblados; Lázaro Aljure monta el Hotel Pacífico, en el lugar que hoy ocupa la sede principal de Bancolombia y luego por las mismas razones incursionó en el transporte con el primer carro que transportaba pasajeros a Golondrinas, sitio hasta donde llegaba el tren entonces: "fue quizá el turco más conocido y simpático del Huila, a quien la gente le adjudicó el mayor número de cuentos y leyendas" (Hakim 1993). Hacia 1930, Teófilo Zajar llegó a Neiva y le compró el Gran Hotel Imperio a su propietario Ricardo Dussán León; lo mantuvo durante más de 10 años y en 1943 se lo vendió a otro árabe, León Galat; ese hotel aún funciona en Neiva en el mismo lugar, por la calle octava frente al Diario del Huila; León Galat lo preservó hasta cuando decidió trasladarse definitivamente a Bogotá sin dejar parentela en la ciudad o la región; quienes lo conocieron afirman que era un personaje conservador y apasionado por las ideas de derecha. Y en 1948, los hermanos Elías y Teófilo Zajar montaron el Hotel Atlántico en una casona vieja con un amplio y arborizado patio, ubicada en donde hoy funciona el Edificio Metropolitano; las características personales de Elias Zajar - según Hakim, espontáneo, buen conversador y alegre- y el ambiente que emanaba la estadía en el hotel, hicieron que este concentrara la poca clientela que en ese entonces demandaban los hoteles, al punto que parecería ser la razón por la que León Galat decidió dejar el gran Hotel Imperio e irse a Bogotá.

Al transporte también se vinculó Atala Tapicha, el sirio propietario del almacén más próspero en los años treinta llamado El Buen Gusto, donde vendía aceitunas españolas y griegas en barriles, vinos italianos y franceses, pasabocas como pistachos, almendras, maní, así como etaminas de Suiza, radios de Alemania, muebles de mimbre de Austria, anchoas, aceite de oliva en galones, sardinas en lata, mariscos, trigo americano con el que preparaban los famosos quipe o quibe, tabule y pan árabe; era dueño también del automóvil más lujoso de los únicos ocho que había en la ciudad en 1934 y que eran parqueados en el Parque Santander.

Como la luz eléctrica solo llegó a la ciudad en 1914 y ello prolongó el día aunque la ciudad siguió siendo la misma, es decir, la vida social se reducía a la rutina de siempre, al marasmo de la cotidianidad del día solar, los Tapicha adquirieron una propiedad rural en las afueras de Neiva y ahí efectuaban reuniones entre parientes y paisanos, donde disfrutaban de prácticas y 
gustos gastronómicos ancestrales; ese lugar se lo vendieron luego al paisano Elias Zajar, el mismo del Hotel Atlántico, quien lo vendería luego a su paisano y pariente Edmundo Aljach Zajar para fundar allí La Cabaña, el primer club social por fuera del perímetro urbano y con servicio nocturno; La Cabaña amplió el tiempo del día y transformó la vida social que ahora tenía un tema más para poner en la agenda de las señoras: la ida a la Cabaña el fin de semana, o el consumo del pollo, el plato preferido del menú. Ezeding Zabag un sirio de los Altos del Golán, mencionado atrás, que llegó en 1982, compró el Restaurante El Caimo y luego tomó en arriendo El Jardín, en las afueras de la ciudad, donde montó un restaurante; a ambos restaurantes acudían las personas pudientes de la ciudad a degustar la comida árabe preparada por él mismo, que había estudiado hotelería, turismo y culinaria en Londres.

Su rutina de trabajo y las percepciones sobre la condición de los migrantes, explicarían las razones que permitían a los árabes hacerse a un capital rápidamente y escalar económica y socialmente: "Yo hace dos o tres años cuando terminé con El Caimo y después de 25 años de trabajo, nunca tuve un día de descanso, ni sábado ni domingo, ni lunes; trabajaba de lunes a lunes; solamente cuando viajaba a otro lado. Pero de lunes a lunes desde las siete $u$ ocho de la mañana hasta las doce o una; ahí en el Caimo cerraba de tres a cinco, tenía una camita, ahí almorzaba, hacía la siesta, otra vez abría a las seis hasta las once, doce, una de la mañana........pues la mayoría cuando llegaron aquí, todos de maletas y camino y vendiendo telas de puerta en puerta y de pueblo en pueblo, no había carros, no había nada. Yo conozco a un señor que ya murió, que viajaba a lomo de mula desde Bogotá hasta Villavicencio, no sé cuántos días se demoraba viajando; era un personaje que comentaba que en el camino encontraba dificultades de lluvia, el frio y ladrones y así todos. Ninguno vino profesional de este tiempo. Ninguno vino de profesor, médico, ni ingeniero y tampoco que escriba (sic) y que lea, la mayoría es analfabeta...digamos eso hace cien años...los que llegamos después de la Segunda Guerra Mundial llegamos con familia. Llegaron unos con bachiller (sic), o la universidad, o todo esto así, llegamos otra tanda."

Ezeding describe igualmente el espíritu del huilense que encontró y que facilitó su rápido crecimiento económico y la fácil articulación a los procesos económicos y sociales: " ...la parte de comercio era muy poco el que jala el huilense, aquí es muy poco el que jala esta actividad de comercio...de verdad no sé cómo era el huilense en esta época, a nivel general, porque ahorita, digamos, el comercio lo tienen más los paisas que el huilense; no sé, debe ser de naturaleza del huilense que no busca....va uno a almacén que atiende el huilense...le da pereza levantarse de la silla y atender bien y si compra está bien y si no compra no le gusta...."(Ezeding Sabbag. 2009)

Hamid Saab nació en Natagaima a los pocos días de haber llegado sus padres del Líbano, en 1925; a finales de 1951 legaron a Neiva, donde se vincularon al comercio con un Almacén, La Costeña, y luego a la producción de arroz para lo cual compraron un molino para degranar; habían comprado maquinaria pesada y como las primeras concesiones petroleras comenzaban a operar con intelcol, se dedicaron a trabajar con ellas.

En conclusión, en el campo económico es evidente que los árabes que llegaron a Neiva se dedicaron esencialmente al comercio, llegando prácticamente a controlar esta actividad en un periodo largo de la primera mitad del siglo XX y parte de la segunda; aunque también penetraron y controlaron la industria hotelera que al mismo tiempo que fue un nicho económico importante de ingresos, sirvió de herramienta esencial para el funcionamiento de las redes sociales entre paisanos que promovieron la inmigración; como se dijo, en el periodo de esplendor de la inmigración de árabes a Neiva y el Huila en la década de los veinte, treinta, cuarenta y cincuenta, los tres más importantes hoteles de la ciudad eran de propiedad de árabes y de los 15 almacenes de telas y mercancías que se concentraban en torno al Parque Santander y sus dos arterias de acceso más relevantes, la carrera quinta y la calle octava, los ocho más grandes y de mayores ventas eran de árabes (Eduardo Rujana Quintero. 2009).

Con respecto a las razones que explicarían la rápida articulación de los árabes a la vida social de Neiva debe decirse que además de ser abiertos, la población nativa vivía aislada y desconectada del país y del mundo; por eso sentía la necesidad de abrirse y conocer y esa posibilidad la veían a través de los árabes, que se sabía conocían otros mundos, ya que muchos, además del árabe hablaban francés. Los árabes constituyeron para la mayoría huilense, incluyendo a la propia élite, la posibilidad de conocer otro mundo; de saber que más allá del terruño existían otras realidades y que estos hombres eran expresión y consecuencia de ellas. De ahí que mas allá de que los árabes propendieran por articularse a la nueva realidad a la que llegaban para quedarse definitivamente y echar raíces o volverse después de haber hecho capital, fueron los pobladores nativos los que ansiosos articularon a aquellos al seno de la sociedad, buscando seres diferentes desde los cuales buscarse a sí mismos, encontrar su propia identidad. Seres físicamente maravillosos, para algunos como los productores de la película La Vibora, que requerían de un antagonista bonito que coprotagonizara el film al lado de Fernando González Pacheco y que vieron en Hamid Saad el actor apropiado.

Las versiones de Hakim, Rujana, Plazas Alcid, Alma Lucía Abauat, Hamid Saab, Edmundo Aljach, Tonny Freiye y Ezedin Sabag coinciden en que las élites de Neiva buscaban ansiosas la amistad de los árabes y ser invitadas a sus reuniones sociales; no hubo pues, aversión o rechazo de las élites o de la población receptora contra los árabes, con excepción de una sola oportunidad, en la que los protagonistas fueron hijos 
de árabes nacidos en Colombia; en esa oportunidad se realizó un reinado en el que quedaron dos candidatas finalistas; la una representaba a los barrios de la ciudad y la otra a las entidades oficiales; un hijo de árabe que tenía un almacén y buenos recursos económicos puso todo lo necesario para que ganara la candidata preferida, esta última; y ganó; los asistentes a la velada salieron y destrozaron los vidrios de los almacenes de los árabes y por primera vez se escucharon en Neiva voces públicas de rechazo contra los árabes; por supuesto, seguramente fue un detonante para expresar un sentimiento privado, que en el país no era extraño; desde 1910 en un medio local en Ocaña, se expresaban sentimientos contra los "turcos" porque consideraban incomprensible cuando no extraño que en tan poco tiempo y de la nada se hicieran a sumas significativas de capital solo mercadeando cachivaches. Pues ese sentimiento seguramente afloró en Neiva también a mediados de siglo.

Esa aversión desde lo popular, hacia una población que llegó sin muchos recursos pero sin prevenciones sociales ni culturales podría explicarse no tanto en el hecho de que estos señores acumularan capital rápidamente, puesto que el rechazo no fue de las élites, sino en el hecho de que por ese capital acumulado las élites se hubieran reunido en torno a ellos; o sea que el rechazo a los árabes sería considerado como un rechazo a la élites a las que ellos se unieron.

Hoy quedan en Neiva y el Huila muchos herederos de esas familias de inmigrantes que llegaron desde finales del siglo XIX y aumentaron a comienzos y mediados del XX; los hijos que quedan son viejos y sus edades hacen que su condición de salud sea de cuidado; sobrevive Edmundo Aljach; los otros son nietos de inmigrantes, como Eduardo Rujana, Guillermo Plazas, Alma Lucía Abauat y muchos otros que no se abordaron para este estudio; la generación joven es la de los bisnietos; esos sí son muchos y transitan por los caminos de la vida de la ciudad y del departamento; sus apellidos se confunden con los de la población nativa y en muchos casos han desaparecido por ocupar lugares terciarios que ya no cuentan en la identidad personal. Otros porque por temor al estigma castellanizaron sus nombres o apellidos como en el caso de los Lara (Larach), de los Durán (Doura, en árabe) o de los Guerra, de cuya presencia en el Huila no tuvimos certeza, y cuyo apellido original era Harb; tampoco de apellidos que tenían diversas variantes dado que su significado original era Hijo de cura, para mencionar el patronímico de quienes eran hijos de sacerdotes maronitas que por poderse casar tenían hijos a quienes ponían ese apellido, Al Jure, o El Khoure, y que fueron fonetizándose al castellano como Cure, Curi, Aljuri o Aljure, apellido este último que se preserva en el Huila, y muchos en las costa atlántica, los primeros.

\section{Referencias Bibliográficas}

ECHEVERRY Juan Álvaro (Territorio como Cuerpo y Territorio como Naturaleza: ¿diálogo intercultural?) y ARDILA Gerardo (Ingeniería Y Territorio: Una Relación Política Indisoluble. Transcripción de la conferencia dada en San José de Costa Rica a los Ingenieros del Instituto costarricense de energía.2005) en Revista de antropología, departamento de antropología. Universidad de Costa Rica. 2006.

TOVAR Z. Bernardo."La economía huilense. Entre la tradición y la modernidad (1900-1960)".Historia General del huila. Vol.3. Neiva 1996.

TOVAR Z. Bernardo. "El Huila, el ordenamiento territorial y la región Surcolombiana." En Insurgentes. Construir región desde abajo. Ed. Universidad surcolombina.2003.

MARTINEZ C. Héctor Jaime y MARTINEZ c. Rocío. "Economía y región. Aproximación a la historia del siglo XIX en el Huila." Historia general del Huila. Vol 3. Neiva 1996.

OSORIO, Ananías. Empresas y vías de transporte. Historia general del Huila. Vol 3. Neiva 1996

GONZALEZ A. José Jairo. Las colonizaciones opitas. Historia General del Huila. Vol 3. Neiva 1996.

TRILI.ERAS R. Alvaro. Baraya: su historia, sueños y temores. Neiva 2003.

QUINTERO, B, Alexander. "Hacendados, negociantes, y comerciantes deNeiva

1870-1900. Trabajo de grado para maestría en la Universidad del Valle. 20

ESGUERRA CAMARGO, Luis. El inmigrante en nuestra legislación ". Revista de las Indias. Bogotá junio de 1939.

FERNÁNDEZ DE SOTO, León. Inmigración en Colombia. Tesis de grado para optar el título de doctor en Derecho y Ciencias políticas. 1946. Hemeroteca Nacional.

BAUTISTA. Julián F. La inmigración extranjera y los procesos de desarrollo económico y modernización en Colombia. (1930.1950)". Tesis de grado para optar al título de Sociólogo. Universidad Nacional de Colombia. 1995.)

HECTOR ROMANO MARUN. "Breve historia del Líbano". Plaza y janés. Bogotá 1985.

GLADYS BEHAINE DE CENDALES.. "Anotaciones sobre inmigraciones libanesas a Colombia". En Revista Javeriana, Tomo XCIV. No 467. 1996.

NATALIA RINCON. "Arabes y judíos en Colombia: un modelo de integración social". En Memoria y Sociedad. Vol 7. No 13. Noviembre 2002.

DACCARETT, ENRIQUE YIDI , DACCARETT, KAREM DAVID Y OTRA "La migración árabe en la construcción cultural del departamento del Atlántico. 1905-2005." Ed. Uninorte. Barranquilla 2007.

GLADYS BEHAINE DE CENDALES. "Situación política del Líbano" En Revista Javeriana, Tomo XCIV. No 470

HAKIM MURAD, Eduardo. "El murmullo de los cedros".Ed. Eduardo Hakim Murad. Neiva 1993.

HAKTM MURAD, Eduardo. La piel del puercoespín. Neiva. 1987

FALS BORDA, y otros. "Insurgentes. Construir región desde abajo. Universidad Surcolombiana. 2003. Particularmente los textos "El rostro ambiguo de Colombia" de Daniel Pecaut; "el Huila, el ordenamiento territorial y la región Surcolombiana" de Bernardo Tobar Zambrano; y "Construir desde abajo: subjetividades en la región Surcolombiana" de William Fernando Torres e Hilda Solead Pachón.

TORRES, William Fernando y otros. "Historia de la sierra y el desierto. Conflictos culturales en el Huila entre 194 y 1995". Universidad Surcolombiana, ICAM, Red de Solidaridad social. Neiva 1995.

GUARNIZO, Luis Eduardo. Colombia: migraciones, transnacionalismo y desplazamiento. Migración, globalización y sociedad: teorías y tendencias en el siglo XX. Cátedra Manuel Ancízar. Facultad de Ciencias Humanas. Universidad Nacional de Colombia. Colección CES. Primera edición. Bogotá noviembre de 2006.)

TORRES, William Fernando. "De la insularidad al naufragio". En Huila: años 80 . Economía, política y cultura. Universidad Surcolombiana. Neiva. 1982 